\title{
How the COVID-19 Pandemic Affected Developing Countries: the Tunisian Investigation
}

\author{
Mohamed Ali Labidi ${ }^{1}$
}

Received: 5 April 2021 / Accepted: 17 December 2021

(C) The Author(s), under exclusive licence to Springer Science+Business Media, LLC, part of Springer Nature 2021

\begin{abstract}
The consequences of COVID-19 vary considerably from country to country and from sector to sector. In this paper, we examine how employment in sectors of Tunisian economy is being affected by the COVID-19 pandemic. For this purpose, we apply the Markov chain approach. This method has the merit to model a system that changes states according to a transition rule that depends only on the current state. We find that the COVID-19 have a negative impact on the employment in industry and in service. Moreover, the agricultural sector benefits most from COVID-19. It is important to plan for economic measures in order to support the resilience of economic establishments, particularly small- and medium-sized enterprises.
\end{abstract}

Keywords Employment · Industry · Agriculture · COVID-19 · Markov chains · Tunisia

\section{Introduction}

The COVID-19 pandemic is global shock and is the most acute global crisis of our time. It reflects the structural weaknesses of many countries and exacerbates economic inequalities. While countries have to face the consequences of the pandemic, policy makers seek effective and balanced solutions to address both: the public health challenges and the needs of economic recovery. Although it is too early to specify what economic implications of the COVID-19 pandemic will be, economists largely agree that it will have serious negative impacts on the global economy (Makoni, 2020; Maliszewska et al., 2020; Ozili \& Thankom, 2020).

Mohamed Ali Labidi

mohamedali.labidi@fsjegj.rnu.tn

1 Laboratory of Valorization of Natural and Cultural Heritage, University of Jendouba, Jendouba, Tunisia 
Observers highlight the fact that the economic damages caused by the COVID19 pandemic are largely driven by a fall in demand (Ascani et al, 2020; Montenovo et al., 2020; Yagan, 2019). This may affect job creation, and unemployment is likely to increase sharply (Coibion et al., 2020a, b; Forsythe et al., 2020; Guerrieri et al., 2020). In the case of Tunisia, such a scenario would be catastrophic for the economy as the unemployment rate is already persistent and excessively high.

The massive and brutal shock caused by the corona virus pandemic and by the business interruption measures taken to stem it represents the deepest global recession since World War II. Indeed, an unprecedented number of countries have witnessed a decline in their production per capita. As a result, economies are slowed down, causing many businesses to face disruptions in demand and supply chains; many of their employees stayed at home and were, therefore, unable to ensure production and service delivery.

Developing countries were relatively spared from the consequences of the international financial crisis of 2008. However, COVID-19's crisis has caused severe recessions. The collapse of trade and investment, commodity prices, and the drying up of external sources of finance were the main channels of transmission of the crisis to developing countries. Thus, vulnerable populations will, likely, pay the heaviest price bringing social issues back to the fore. Forecasts point to a significant drop in per capita incomes. That will cause unemployment and, possibly, extreme poverty over years. Indeed, lower middle-income countries (LMIC) find themselves in a particularly difficult position to deal with it. Hard hit by external shocks, LMICs undergo strong internal contractions caused by the spread of the virus and by the containment measures aimed at containing it. At the same time, scarce resources and weak institutions have limited the ability of many developing country governments to support their country's economy. For that, developing countries' priority was to deal with the economic emergency. They must find solutions that restore economic recovery and tackle deepening poverty and unemployment.

The crisis caused by the COVID-19 pandemic was exceptional. It was shaped up to be the most severe recession in advanced economies since World War II. In these economies, economic activity was experiencing serious disruptions that have hit domestic supply and demand, as well as trade and finance. Developed countries that lean heavily on world trade, tourism, and exports were considered to be the most affected by the crisis.

Tunisia has long stood out on the African continent by solid growth, by its openness to foreign trade and foreign investment in the "offshore" sector, but also by better results than its neighbors in terms of reducing the rate of unemployment, health, education, poverty reduction, and gender equality (Diwan, 2019; Labidi, 2019). Tunisia, after almost perfectly handling the first wave of COVID-19 in mid-2020, the country fell into a deep political, economic, and later health crisis. In this context, an immediate priority for the Tunisian government is to understand the extent to which the COVID-19 will affect employment in the different economic sectors. In fact, this study examines the impact of COVID-19 on the Tunisian employment. Compared to the work carried out until now, the novelty of this research lies in using the Markov Chain process to determine what will happen in the long run once the pandemic is gone. The Markov chain model is well suited to predict the structural 
changes, such as those caused by the COVID-19 pandemic when the discrete states are easy to distinguish.

The remainder of the paper is organized as follows. "The Evolution of Tunisia's Employment Policy" section presents the evolution of the employment policy in Tunisia and the measures undertaken to mitigate the effects of COVID-19 on the labor market. "Empirical Studies of the Economic Impact of COVID-19 Pandemic" section reports the main empirical studies of the economic impact of COVID-19. "Model and Empirical Estimation" section presents the methodological and empirical results. The paper concludes with recommendations based on the empirical study and lessons retained from others countries.

\section{The Evolution of Tunisia's Employment Policy}

Employment policy is a set of programs, measures, and initiatives aimed at improving the employment situation or alleviating the consequences of unemployment. Initiatives in these fields are multiplying in all countries and concern all levels of government including the local level (Jacob \& Genard, 2011). At the level of active interventions, public interventions generally focus on the key concepts of employability, adaptability, flexibility, activation, learning, entrepreneurship, and social inclusion.

In the last decade, employment policy has become a priority in Tunisia. In fact, there have been many measures taken in terms of employment policy, especially after the 2011 revolution. These policy measures aimed, mainly, at reducing tensions in the labor market: gaps between job supply and demand, a gap between the profiles of job seekers and those profiles sought by companies (Boughzala et al., 2020). These tensions are likely to worsen due to economic changes that have significantly changed the economic landscape both at national and regional levels (Rama, 1998). Regional productive systems have had to adapt to the new context of globalization and to technological or organizational innovations. In fact, in the coastal regions, the productive systems went from a high level of industrialization to a tertiarization of economic activity branches. However, the regions of the interior of the country were catching up in terms of industrialization.

In Tunisia, active employment policies constitute the main instrument of the public authorities to deal with unemployment. The actions of those involved in the implementation of active employment policies can be classified into three programs: programs linked to training insertion, programs seek to promote micro-enterprises and initial and continuing vocational training programs. The employment policy implemented by these different bodies represents all public interventions aimed at increasing the number of available jobs or at reducing the number of unemployed. After the Arab Spring of 2011, Tunisia began to develop comprehensive national employment policies. It has moved from active labor market policies limited to young graduates to more comprehensive policies addressing the many other employment problems encountered in the region.

The labor market in Tunisia is characterized by permanent tensions and large gaps between employment supply and demand. Indeed, the labor market does not 
succeed in making the matching between supply and demand. Containment measures do affect employment. In fact, before the start of the pandemic, 2/3 of the working population was working in the most affected sectors by the crisis: manufacturing industries, the trade and the distribution sector, accommodation, and catering. Companies that were forced to close and were not able to opt for teleworking have had to suspend their activity and resort to partial unemployment for their employees.

The most affected sectors in Tunisia are those of specialized, scientific, and technical service activities, trade, construction, accommodation, and catering. Added to that, the cessation of all informal economic activities leads to an increase in the unemployment rate and to an unequal access to employment. The recruitments of Tunisian companies during the corona virus crisis, like many other countries, focused on certain human resources functions, expertise in IT, agri-food, pharmaceutical sector, and on the greater distribution.

The Tunisian labor market and its functioning are deeply impacted by the COVID-19. Containment and social distancing may explain the increased frequency of work stoppages for those whose activity requires frequent contact with the customer. The effects of the corona virus crisis will last for years to come. Thus the resumption of economic activity would not help quickly absorb the job losses that marked the year 2020, moreover, Tunisian companies today lack short- and mediumterm visibility on their activity and on the recovery of their sector.

The Tunisian economy is very open to the rest of the world and, therefore, very vulnerable to exogenous shocks. In particular, the retraction of foreign trade with the European partners cost more than 2 points of economic growth in 2020. As a result, all sectors except agriculture and fisheries have experienced negative growth rates in the added value. The socio-economic impact of COVID-19 prompted the Tunisian government to set up a committee responsible for monitoring the companies most affected by the crisis. In addition to tax breaks and amnesty for customs disputes, these companies can benefit from a rescheduling of their debts over 7 years. For certain sectors such as tourism, catering, crafts, transport, or culture, a mechanism is set up to guarantee access to new loans granted by banks over a period of 7 years with 2 years of thanks. From its part, the Central Bank reduced the key interest rate by 100 basis points to $6.75 \%$ and proceeded to postpone the repayment of loans to businesses and individuals ranging from 3 to 6 months. In addition, the Ministry of Social Affairs has launched an action plan to help the groups most affected by the crisis.

From a small country with strong demographic growth and dominant agricultural activity, Tunisia has, greatly, diversified its activity towards industry and services after 70 years of independence. In the actual environment, which made more restrictions by globalization and by COVID-19 pandemic, it seemed interesting to take stock of the sectors of activity in Tunisia in terms of their participation in the job creations.

Before the 2011 revolution, the growth rate of the Tunisian economy remained strong (4.5-5.5\%). This growth, accompanied by strong investment in human resources and collective infrastructure and services, helped to reduce the poverty rate. The budgetary structure has maintained a high level of public debt. The major macroeconomic balances (current account, inflation, etc.), however, have been preserved. During this period, economic growth has reduced the 


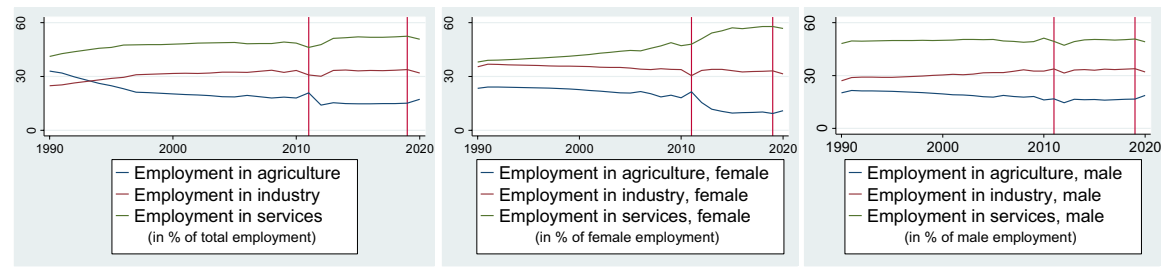

Fig. 1 Employment evolution, by sector and sex, Tunisia, 1990-2020

unemployment rate for women and men (Fig. 1). However, the last decade has been marked by an increase in the unemployment rate. Indeed, the decline in economic growth and in imported exports has had direct effects on employment. The most pronounced increase in the unemployment rate was seen in 2011 and after the lockdown linked to the COVID-19 pandemic.

The evolution of sector activity' employment is the most striking feature of the Tunisian economy. Indeed, since the 1990s, the increase in salaried employment in the industrial and the service sectors has come at the cost of a deceleration in salaried employment in the agricultural sector (Fig. 2). The evolution of sex salaried employment confirms the general trend that is characterized by an increase in the salaried employment of women and men in the industrial sectors and a significant decline in the agricultural sector. In addition, the disruptions linked to the COVID-19 pandemic affected the production, the processing processes, and the transportation of products to consumption centers. Indeed, it has influenced the salaried employment in the industrial and the food sector' services, greatly. The confinement imposed on the population, too, has affected the functioning of agriculture and the demand for agricultural products. However, the agricultural sector has been more resilient than other economic sectors. Indeed, the poor global economic situation has severely limited Tunisia's possibilities to trade with the usual foreign countries, but with varying degrees depending on the product.

Fig. 2 Tunisia unemployment rate, 1990-2020

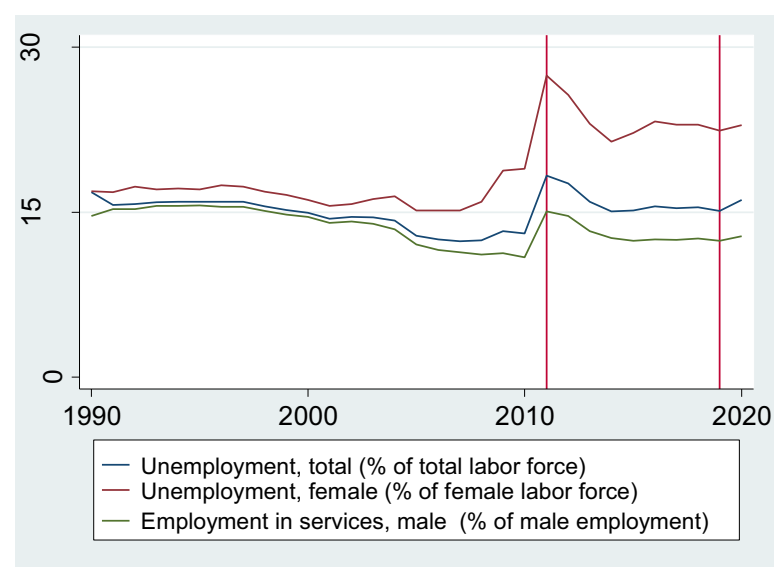


Reducing the unemployment rate remains a challenge in an economy where job creation in the private on the decline. Reducing unemployment requires higher growth rates (around 7\%), increase in private investment, and improvement in the total factor productivity and development of higher skilled sectors.

\section{Empirical Studies of the Economic Impact of COVID-19 Pandemic}

Since the COVID-19 outbreak was first diagnosed, it has spread to more than 190 countries. This pandemic is having a notable impact on global economic growth. Estimates so far indicate that the virus could reduce global economic growth by $20 \%$ per month if current conditions persist and could increase the risks of a global economic recession of a magnitude similar to that experienced during the Great Depression of the 1930s (Coibion et al., 2020b; Cowan, 2020).

Jackson et al. (2020) provided an overview of the global economic costs of the COVID-19 pandemic and the response of governments and international institutions to deal with these effects. The authors showed that world trade could decline from 13 to $32 \%$, depending on the depth and the extent of the global economic recession.

Fernandes (2020) examined the economic impact of COVID-19 on industries. He provided estimates of the potential global economic costs of COVID-19 and of the GDP growth of different countries. Due to over-reliance on historical comparisons with SARS and the 2008-2009 financial crisis, the author has shown that the economic effects of the epidemic are currently underestimated. Service-oriented economies, in particular, will be negatively affected and will have more jobs at risk. Countries like Greece, Portugal, and Spain, which depend largely on tourism (more than $15 \%$ of GDP), will be more affected by this crisis. This current crisis has spillover effects on all supply chains. Consequently, countries that highly depend on foreign trade are the most affected. The results suggest that each additional month of crisis costs 2.5 to $3 \%$ of global GDP, on average.

Bonet-Morón et al. (2020) tried to assess the regional economic impact of containment measures that were ordered by the national government to prevent the spread of COVID-19. The results show that the monthly economic losses represent between 0.5 and $6.1 \%$ of national GDP depending on the scenario considered. Accommodation and food services, real estate, administrative services, construction, and commerce are the most affected sectors. Abiad et al. (2020) have shown an unpredictable impact of the epidemic. He suggests a global impact of $\$ 77$ billion to $\$ 347$ billion or 0.1 to $0.4 \%$ of global GDP with an estimate of moderate case of $\$ 156$ billion or $0.2 \%$ of global GDP.

Ahmed et al. (2020) showed that China's economic growth is expected to fall to $5.6 \%$; investment policies and fiscal policies are expected to implement $\$ 3.3$ trillion and contribute to an additional \$ 4.5 trillion. The projected GDP ratio of $3.0 \%$ in 2019 will increase by $10.7 \%$ in 2020 . The US ratio is expected to rise from $5.8 \%$ to $15.7 \%$. France, Germany, Italy, Japan, and the UK each reported public sector funding programs totaling more than $10 \%$ of their annual GDP. 
Fana et al. (2020) have shown that the pandemic's impact on employment is asymmetric within and between countries. Due to their productive specialization and labor market institutions, Spain and Italy as well as the UK are most likely to suffer the worst consequences of lockdown on employment. Indeed, the labor markets were the most vulnerable before the crisis. They were characterized by high unemployment and precarious work (especially temporary contracts).

Chetty et al. (2020) showed that high-income people sharply reduced their spending in mid-March 2020, especially in regions with high COVID-19 infection rates and in sectors that require in-person interaction. This reduction in spending has significantly reduced the income of small businesses. These companies lay off large numbers of their workers causing widespread job losses, especially among the low-wage workers in other areas. While, high-wage workers experienced a "V-shaped" recession that lasted few weeks, low-wage workers suffered wider job losses that persisted for several months. The authors estimated the causal effects of policies aimed at mitigating the negative impacts of COVID-19.

Kramer and Kramer (2020) focused on areas in which the profession may be affected by the pandemic. First, perceptions of the value and the status of different professions can change, leading to changes in the professional supply and demand (macro-changes) and in the perceived vocation and meaning of different professions (micro-changes). Second, the great "work from home experience" can change professional outlook on working from home. Organizations and researchers may be able to better understand what work, and individual characteristics are associated with the effectiveness of working from home, and better designate occupational groups and individuals to work or not from home.

Atkeson (2020) aims to present a simple SIR model of the progression of COVID-19's impact in the USA over the next 12 to 18 months. An SIR model is a Markov model of the spread of an epidemic in a population in which the total population is divided into categories of being susceptible to disease (S), actively infected with disease (I), and recovered (or deceased) and more contagious (R). How an epidemic unfolds over time is determined by the transition rates between these three states. This model allows for quantitative statements regarding the trade-off between severity and timing of disease suppression through social distancing and disease progression in the population. The author pays particular attention to the question of whether and when the fraction of infections in the population exceeds $1 \%$ (at this stage, the health system should be seriously damaged) and $10 \%$ (which can lead to serious staff shortages for key economic infrastructure).

Wang and Flessa (2020) used an inhomogeneous Markov chains to determine the course of the pandemic through a (SIR) model. They showed that there is uncertainty in the biological and medical facts. That is, the most medical parameters are unknown or highly uncertain. For example, we do not know exactly the relevance of the viral load, the determinants of case fatality rates, and the influence of previous infections with other corona viruses or general immunity. 


\section{Model and Empirical Estimation}

\section{Data}

The empirical analysis is based on a dataset collected from both the Tunisian National Institute of Statistics and from the World Bank spanning 1991-2020. Three activity sectors were considered: agriculture, industry, and service. Furthermore, it includes the added value of both industry and agriculture to deepen the understanding of the employment situation in Tunisia. The definitions of variables are presented in Table 1.

Table 2 reports descriptive statistics. The figures reveal that the percentage of employed people in the service sector is the highest (about 50\%), followed by industry (33\%), and ultimately agriculture (19\%). The added value of the industry is nearly three times as large (27\%) than that of agriculture (11\%). This can account for the higher employment rate in industry as compared to agriculture. This claim is also supported by the positive high correlation (0.7) between IAV and ES and (0.6) between IAV and EI (Table 3). When looking at dispersion (standard deviation) of each variable, one can note that this dispersion varies from $(0.01)$ to $(0.03)$. This explains why the magnitude of the variation is relatively weak for all variables.

\section{Empirical Estimation and Discussion}

The aim of this paper is to predict the economic changes that are likely to be experienced in employment in the different economic sectors in Tunisia as a result of the COVID-19 pandemic. The analysis is based on the Markov chain model.

The general idea is to model a random system that changes states according to a transition rule that only depends on the current state. Let $y_{t}$ be a vector of observed variables, and let $s_{t}$ denote an unobserved random variable. $s_{t}$ is as an irreducible, a periodic Markov chain starting from its ergodic distribution. The probability that $s_{t}$ is equal to $j$ depends only on the most recent realization, $s_{t-1}$, and is given by the following expression:

$$
\operatorname{Pr}\left(s_{t}=j \mid s_{t-1}=i\right)=p_{i j} \text { for } \mathrm{i}, \mathrm{j}=\mathrm{I}, . ., \mathrm{K}
$$

All possible transitions from one state to the other can be collected in a $k \times k$ transition matrix:

$$
P=\left(\begin{array}{ccc}
p_{11} & \ldots & p_{k 1} \\
p_{12} & \ldots & p_{k 2} \\
\vdots & \ddots & \vdots \\
p_{1 k} & \ldots & p_{k k}
\end{array}\right)
$$

Note that all elements of $P$ (the transition probability matrix) are non-negative, and each column sums to 1 (Hamilton \& Susmel, 1994; Sylvia, 2006). The variable, $s_{t}$, is regarded as the state or regime that the process is in at date $t$. By this, we mean 
that $s_{t}$ governs the parameters of the conditional distribution of $y_{t}$. If the density of $y_{t}$, conditional on its own lagged values and on the current and previous $q$ values for the state is of a known form, the methods developed in Hamilton (1989) can be used, then, to evaluate the likelihood function for the observed data and make inferences about the unobserved regimes.

The variable, $s_{t}$, is regarded as the state or regime that the process is at date $t$. By this we mean that $s_{t}$ governs the parameters of the conditional distribution of $y_{t}$. If the density of $y_{t}$, conditional on its own lagged values and on the current and previous $q$ values for the state is of a known form, the methods developed in Hamilton (1989) can be used, then, to evaluate the likelihood function for the observed data and make inferences about the unobserved regimes.

Consider the evolution of $y_{t}$, a random system that is characterized by two states or regimes as in the models stated below:

$$
\begin{gathered}
y_{t}=\mu_{1}+\varnothing y_{t-1}+\varepsilon_{t} ; \quad t=1, . ., T \\
y_{t}=\mu_{2}+\varnothing y_{t-1}+\varepsilon_{t}
\end{gathered}
$$

where $\mu_{1}$ and $\mu_{2}$ are the intercept terms in state 1 and state 2 , respectively; $\varnothing$ is an autoregressive parameter; and $\varepsilon_{t}$ is a white noise error.

The two states model abrupt shifts in the intercept term. If the timing of switches is known, the above model can be expressed as follows:

$$
y_{t}=s_{t} \mu_{1}+\left(1-s_{t}\right) \mu_{2}+\varnothing y_{t-1}+\varepsilon_{t}
$$

where $s_{t}$ is 1 if the process is in state 1 and 0 otherwise. Estimation in this case can be performed using standard procedures.

In the case of interest, we never know in which state the process is; that is to say, $s_{t}$ is not observed. Markov-switching regression models specify that the unobserved $s_{t}$ follows a Markov chain. In the simplest case, we can express this model as a statedependent intercept term for $k$ states:

$$
y_{t}=\mu_{s t}+\varepsilon_{t}
$$

where $\mu_{s t}$ is the parameter of interest; $\mu_{s t}=\mu_{1}$ when $s_{t}=1$, and $\mu_{s t}=\mu_{2}$ when $s_{t}=2$.

Although one is never certain in which state the process lies, the probabilities of being in each state can be estimated. According to the Markov process, the transition probabilities are of greater interest. Transition probabilities are given by $p_{s t, s t+1}$. Hence, for a two-state process, $p_{11}$ denotes the probability of staying in state 1 in the next period given that the process is in state 1 in the current period. Likewise, $p_{22}$ denotes the probability of staying in state 2 . Values closer to 1 indicate a more persistent process. It is expected to stay in a given state for a long time.

Our aim is to determine the value of the transition probability, which will be very important in analyzing the post COVID-19 implications on employment. To that end, we have paid particular interest for the number of states (or regimes) to be selected. From Fig. 3, which displays the distribution of the five variables under study, we notice that from 1991 to 2020, all variables display either 

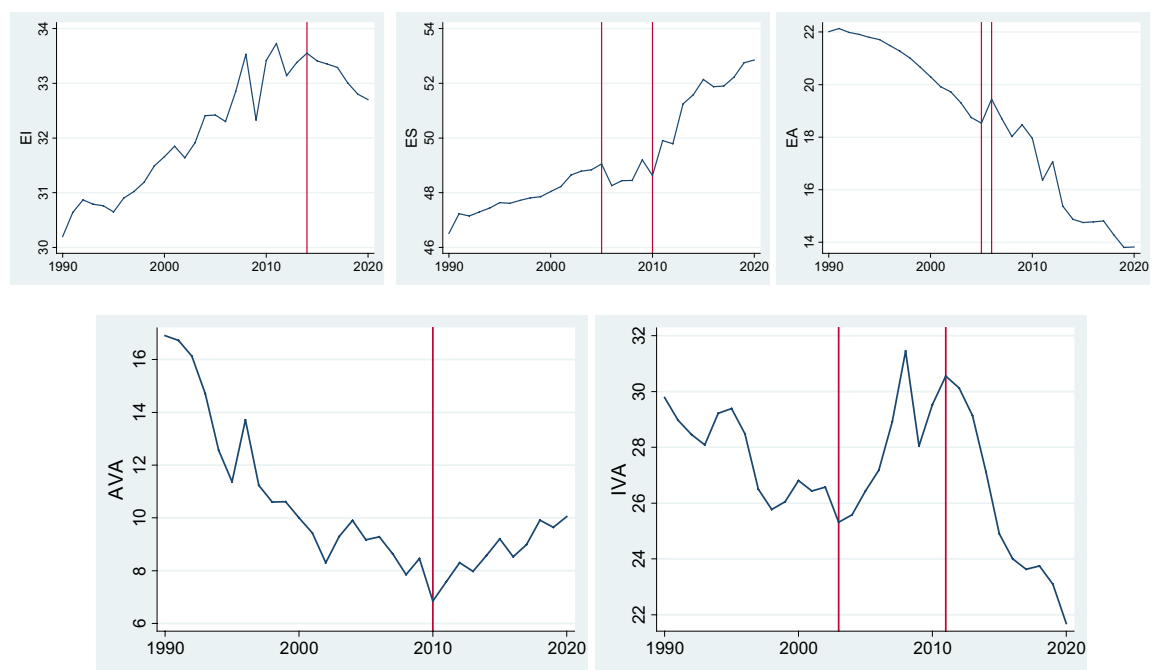

Fig. 3 Distribution of variables under the study

downward or upward movements. Furthermore, Fig. 3 reveals an interesting observation: variables can be grouped according to their states into two groups: group 1 consists of variables that are in the $s_{1}$ in an ascending flow (upward) and in the $s_{2}$ in a descending flow (downward). Variables of the second group are in the reverse situation. Particularly, we observe that EA, IAV, and EI belong to group 1, while ES and AAV belong to group 2.

Table 4 represents the transition probability estimates. It provides information regarding the behavior of the five variables under study, namely, ES, EI, EA, IAV, and AAV, changing from one state to another. However, results of the transition probability are collated in Table 5 .

Each variable is considered as a Markov process with four observed transitions (or jump), transiting from state 1 to state 2. $p_{11}, p_{12}, p_{21}$, and $p_{22}$ represent the probability of the Markov process changing from one state to another. For example, if the Markov process related to employment in service (ES) is in $s_{1}$, the probability it changes to $s_{2}$, then, is 0.03 . However, the probability it remains in $s_{1}$ is 0.97 .

The results of the probabilities of change after the COVID-19 pandemic are reported in Table 6.

Table 1 Variables and their definitions

\begin{tabular}{ll}
\hline Variable & Definition \\
\hline ES & Employment in service (\% of total employment) \\
EI & Employment in industry (\% of total employment) \\
EA & Employment in agriculture (\% of total employment) \\
IAV & Industry added value (\% of total added value) \\
AAV & Agriculture added value (\% of total added value) \\
\hline
\end{tabular}


Table 2 Descriptive statistics

\begin{tabular}{llllll}
\hline Variable & Obs & Min & Mean & Std. Dev & Max \\
\hline ES & 30 & 0,4627 & 0,4938 & 0,0258 & 0,5542 \\
EI & 30 & 0,3037 & 0,3213 & 0,0105 & 0,3373 \\
EA & 30 & 0,1293 & 0,1848 & 0,0330 & 0,2336 \\
IAV & 30 & 0,2211 & 0,2686 & 0,0240 & 0,3145 \\
AAV & 30 & 0,0753 & 0,1038 & 0,0229 & 0,1672 \\
\hline
\end{tabular}

The estimated probabilities of changing from one state to another suggest that 4 among the 5 variables seem to be negatively affected by the COVID-19 pandemic. This fact indicates that COVID-19 is likely to damage the employment situation. For instance, for the first group of variables in which the S1 are in an ascending flow and the $s_{2}$ are in a descending one, we notice that for 2 of the 3 variables, namely, EI and IVA, the probability of being in $s_{2}$ is higher than that of being in $s_{1}, 55.38 \%$ as compared to $44.61 \%$ and $49.14 \%$ as compared to $50.85 \%$, respectively. This fact supports the idea that $s_{2}$ is more likely to take effect. Hence, for EI and IVA, the situation is projected to decline because of the COVID-19 virus. For the second group, similarly, we observe that for both variables, ES and AAV, the probability of being in $s_{1}$ is higher than that of being in $s_{2}, 63.13 \%$ as compared to $36.86 \%$ and $67.66 \%$ as compared to $32.33 \%$, respectively. This suggests that for ES and AAV, future projections call for a deterioration of the situation. One possible explanation of these finding is that the industry in Tunisia is concentrated in activities with low added value, and the exporting activities are only related to the world trends. Today, the COVID-19 pandemic will stop global economic activity and force countries to close their borders and stop all their trade with the outside world. This will cause an economic recession, even of short duration. A recession will, certainly, affect employment.

In relation with the employment in agriculture (EA), Table 6 shows that the probability of being in an ascending flow (upward) is about $87.68 \%$ as compared to $12.31 \%$ of the probability of being in a descending one (downward). It appears that the EA may get better after the COVID-19 pandemic. Two reasons might explain this finding, namely, the low contribution of agriculture in economy and the fact that it is being under exploitation.

Table 3 Correlation matrix

\begin{tabular}{lrrlll}
\hline & \multicolumn{1}{l}{ ES } & \multicolumn{1}{l}{ EI } & EA & IAV & AAV \\
\hline ES & 1.0000 & & & & \\
EI & 0.5711 & 1.0000 & & & \\
EA & -0.9660 & -0.7639 & 1.0000 & & \\
IAV & 0.7031 & 0.6012 & 0.5714 & 1.0000 & \\
AAV & -0.4035 & -0.7955 & 0.5683 & 0.0989 & 1.0000 \\
\hline
\end{tabular}


Table 4 Markov-switching regression

\begin{tabular}{llll}
\hline & \multicolumn{2}{l}{ Means of the two states $(\mu)$} & $\begin{array}{l}\text { Standard } \\
\text { deviation } \\
(\sigma)\end{array}$ \\
\cline { 2 - 3 } & State 1 & State 2 & 0.010 \\
\hline ES & 0.480 & 0.530 & 0.005 \\
EI & 0.310 & 0.328 & 0.016 \\
EA & 0.146 & 0.204 & 0.014 \\
IAV & 0.250 & 0.287 & 0.011 \\
AAV & 0.094 & 0.141 & \\
\hline
\end{tabular}

When looking at the magnitude of the difference of probabilities between the $s_{1}$ state and the $s_{2}$ state, we clearly point out that the EA exhibits the biggest value followed by AAV and ES. EI and IAV show lower values.

Summing up the results allows us to conclude that the COVID-19 will have a negative impact on the industrial sector and on employment. Although its low contribution in the GDP (just $10 \%$ on average), the agricultural sector will be the biggest winner with an increasing employment rate $87.68 \%$.

Based on the above-mentioned results, it is necessary that the Tunisian government develops fiscal and monetary policies as well as measures that can protect the various sectors of the economy, particularly in agriculture, if it is willing to stay in the race compared to other world economies.

\section{Conclusion and Policy Recommendation}

This paper contributes to the empirical evidence on the economic implications of the COVID-19. This empirical exercise was motivated by the view that a better understanding of the adverse effect of this pandemic could help policy makers to propose proper financial and economic recovery measures for the future.

To empirically test the impact of COVID-19 on employment in the different economic sectors, we relied on the Markov chain models. The results allow us to conclude that the COVID-19 will have a negative impact on employment in industry and service. Although its low contribution in the GDP (just 10\% on average), the agricultural sector will be the biggest winner with an increasing employment rate $87.68 \%$.

COVID-19 has produced shocks in lower middle-income countries. The economic policy recommendations that have emerged for the Tunisian case can, indeed, be generalized for all low-income developing countries. The outlook is very

Table 5 Transition probability

\begin{tabular}{|c|c|c|c|c|c|c|c|c|c|c|c|c|c|c|}
\hline \multirow[b]{2}{*}{$s_{i}$} & \multicolumn{2}{|l|}{ ES } & \multicolumn{3}{|c|}{ EI } & \multicolumn{3}{|c|}{ EA } & \multicolumn{3}{|c|}{ IAV } & \multicolumn{3}{|c|}{ AAV } \\
\hline & 1 & 2 & $s_{i}$ & 1 & 2 & $s_{i}$ & 1 & 2 & $s_{i}$ & 1 & 2 & $s_{i}$ & 1 & 2 \\
\hline 1 & $0.97^{\left(p_{11}\right)}$ & $0.03^{\left(p_{12}\right)}$ & 1 & 0.969 & 0.04 & 1 & 0.957 & 0.043 & 1 & 0.894 & 0.106 & 1 & 0.97 & 0.03 \\
\hline 2 & $0.05^{\left(p_{21}\right)}$ & $0.95^{\left(p_{22}\right)}$ & 2 & 0.031 & 0.96 & 2 & 0.034 & 0.966 & 2 & 0.109 & 0.891 & 2 & 0.06 & 0.94 \\
\hline
\end{tabular}


Table 6 Probability of changes experienced after the COVID-19 pandemic

\begin{tabular}{lll}
\hline & $s_{1}$ & $s_{2}$ \\
\hline ES & $63.13 \%$ & $36.86 \%$ \\
EI & $44.61 \%$ & $55.38 \%$ \\
EA & $87.68 \%$ & $12.31 \%$ \\
IVA & $49.14 \%$ & $50.85 \%$ \\
AVA & $67.66 \%$ & $32.33 \%$ \\
\hline
\end{tabular}

uncertain, however, and is dominated by down side risks, including the assumption of lasting financial turmoil and the weakening global trade and supply chains. The first priority is, then, to deal with the health and the economic emergency in these countries. But beyond that, the international community must unite to find solutions that will re-establish recovery as strong as possible in the low-income developing countries and fight worsening poverty and unemployment.

Lower middle-income countries have to keep their businesses running and to provide them with liquidity through financing, grants, deferral of charges or payments under development programs and employment assistance. However, the budget constraint has limited the stimulus capacities of many low-income developing countries. Added to that, public development banks can support small businesses that do not have access to credit.

Lower middle-income countries will not regain their pre-crisis growth rate because of the irreducible disruptions of production and their excessive weight of the public debt. The down side risks are still high; policy makers, therefore, should be prepared to resort to additional measures to support economic activity. Many developing countries have put in place social transfers in an attempt to mitigate the impact of the pandemic. These measures, however, are not enough to neutralize the shock. Indeed, the effects of the pandemic have been most unequal in countries where pre-existing inequalities were the most marked and are likely to increase the inequality of opportunities in these countries. Thus, the COVID19 crisis is an opportunity to remove obstacles of equal opportunities that previously existed (access to learning, health, quality jobs, child care services, etc.) and that have increased the vulnerability of certain categories of the population. Policy makers must not only mitigate the negative short-term effects of the pandemic on the most disadvantaged households and workers, but also promote inclusive recovery and strengthen the resilience of populations to future shocks by improving access to opportunities for all.

The main observation that can be made that some populations of middle-income countries have been hit harder than others. Women, youth, and poorly educated workers, who were already disadvantaged in the labor market before the shock of COVID-19, have suffered more from job losses due to the immediate impact of the pandemic. Thus, state intervention is essential to provide support to people who have found themselves without a source of income but also to avoid, or at least contain, the loss of jobs. Shedding productive jobs means loss of knowledge and intangible assets in companies, disruption of value chains, and loss of purchasing power that reduces demand. In the case of formal jobs, their elimination also involves 
budgetary costs linked to the loss of tax revenues and social security contributions. Thus, rapid and adequate intervention in the labor markets ensures a source of minimum income, and also a more rapid exit from the economic recession which, very likely, will last well beyond the current health emergency (Coibion et al., 2020a; Forsythe et al., 2020).

Moreover, one of the most disastrous and potentially the most damaging effects of this crisis will only manifest itself in the longer term. Developing countries must, therefore, promote strategies for the informal and the rural economy. Indeed, they must move from political discourse to explicit employment objectives accompanied by concrete measures. This objective can be achieved through a better coordination between the employment policies, the economic and the social context, and the national budget. In addition, policies for vocational training must be activated. Added to that, bodies for labor intermediation should help people find jobs in the most dynamic economic sectors.

\section{References}

Abiad, A., Arao, R. M., Dagli, S., Ferrarini, B., Noy, I., Osewe, P., Pagaduan, J., Park, D., \& Platitas, R. (2020). The Economic Impact of the COVID-19 Outbreak on Developing Asia. Asian Development Bank, Mandaluyong.

Ahmed, Z., Ahmed, O., Aibao, Z., Sang, H., Siyu, L., \& Akbaruddin A. (2020). Epidemic of COVID-19 in China and Associated Psychological Problems. Asian Journal of Psychiatry, 51, 102092.

Ascani, A., Faggian, A., \& Montresor, S. (2020). The geography of COVID-19 and the structure of local economies: The case of Italy. GSSI Discussion Paper Series in Regional Science \& Economic Geography.

Atkeson, A. (2020). What will be the economic impact of covid-19 in the us? rough estimates of disease scenarios. NBER Working Paper 6867.

Bonet-Morón, J., Ricciulli-Marín, D., Pérez-Valbuena, G. J., Galvis-Aponte, L. A., Haddad, E. A., Araújo, I. F., \& Perobelli, F. S. (2020). Regional economic impact of COVID-19 in Colombia: An input-output approach. Regional Science Policy \& Practice, 12(6), 1123-1150.

Boughzala, M., El Lahga, A., Buassida I., \& Ferjani, M. (2020). Les inégalités en Tunisie. Agence française de développement Working Paper.

Chetty, R., Friedman, J. N., Hendren, N., \& Stepner, M. (2020). How did covid-19 and stabilization policies affect spending and employment? A new real-time economic tracker based on private sector data. NBER Working Paper 27431.

Coibion, O., Gorodnichenko, Y., \& Weber, M. (2020a). Labor markets during the COVID-19 crisis: A preliminary view. NBER Working Paper 27017.

Coibion, O., Gorodnichenko, Y., \& Weber, M. (2020b). The cost of the Covid-19 crisis: Lockdowns, macroeconomic expectations, and consumer spending. NBER Working Paper 27141.

Cowan, B. W. (2020). Short-run effects of COVID-19 on US worker transitions. NBER Working Paper 27315.

Diwan, I. (2019). Tunisia's upcoming challenge: Fixing the economy before it's too late. Arab Reform Initiative, Bawader.

Fana, M., Pérez, S., \& Fernández-Macías, E. (2020). Impact de la crise du Covid-19 sur l'emploi: Des effets à court terme aux perspectives à long terme. Journal of Industrial and Business Economics, 47(3), 391-410.

Fernandes, N. (2020). Economic Effects of Coronavirus Outbreak (COVID-19) on the World Economy. IESE Business School Working Paper No. WP-1240-E. https://doi.org/10.22617/BRF200096

Forsythe, E., Kahn, L. B., Lange, F., \& Wiczer, D. G. (2020). Labor demand in the time of COVID-19: Evidence from vacancy postings and UI claims". Journal of Public Economics, 189, 104238. 
Guerrieri, V., Lorenzoni, G., Straub, L., \& Werning, I. (2020). Macroeconomic implications of COVID19 : Can negative supply shocks cause demand shortages?. NBER Working Paper 26981.

Hamilton, J. D. (1989). A new approach to the economic analysis of nonstationary time series and the business cycle. Econometrica, 57(2), 357-384.

Hamilton, J. D., \& Susmel, R. (1994). Autoregressive conditional heteroskedasticity and changes in regime. Journal of Econometrics, 64(1-2), 307-333.

Jackson, D., Bradbury-Jones, C., Baptiste, D., Gelling, L., Morin, K., Neville, S., \& Smith D.G. (2020). Life in the pandemic: Some reflections on nursing in the context of COVID-19. Journal of Clinical Nursing, 29, 2041-2043

Jacob, S., \& Genard, J. -L. (2011). La politique de l'emploi face aux nouveaux modes de gouvernance axés sur la coordination et la performance. Revue Internationale Des Sciences, 77, 551-573.

Kramer, A., \& Kramer, K. (2020). The potential impact of the Covid-19 pandemic on occupational status, work from home, and occupational mobility. Journal of Vocational Behavior, 119, 103442.

Labidi, M. A. (2019). Development policy and regional economic convergence: The case of Tunisia. Regional Science, Policy \& Practice, 11(3), 583-595.

Makoni, M. (2020). Africa prepares for coronavirus. The Lancet, 395(10223), 467-536.

Maliszewska, M., Mattoo, A., \& Van Der Mensbrugghe, D. (2020). The potential impact of COVID-19 on GDP and trade: A preliminary assessment. World Bank, Policy Research Working Paper 9211.

Montenovo, L., Jiang, X., Rojas, F. L., Schmutte, I. M., Simon, K. I., Weinberg, B. A., \& Wing, C. (2020). Determinants of disparities in Covid-19 job losses. NBER Working Paper 27312.

Ozili, P., \& Thankom, A. (2020). Spillover of COVID-19: Impact on the global economy. University Library of Munich MPRA Paper 99317.

Rama, M. (1998). "How bad is unemployment in Tunisia. Assessing labor market efficiency in a developing country. The World Bank Research Observer, 3, 59-77.

Sylvia, F. -S. (2006). Finite mixture and Markov switching models. Springer Series in Statistics.

Wang, M., \& Flessa, S. (2020). Modelling Covid-19 under uncertainty: What can we expect? The European Journal of Health Economics, 21(5), 665-668.

Yagan, D. (2019). Employment hysteresis from the great recession. Journal of Political Economy, 127(5), $2505-2558$.

Publisher's Note Springer Nature remains neutral with regard to jurisdictional claims in published maps and institutional affiliations. 